\title{
An evaluation of candidate geomagnetic field models for IGRF 2000
}

\author{
Susan Macmillan \\ British Geological Survey, Murchison House, West Mains Road, Edinburgh, EH9 1LS, Scotland
}

(Received February 7, 2000; Revised June 9, 2000; Accepted June 15, 2000)

\begin{abstract}
A global evaluation is made of the four candidate models for IGRF 2000 (main field and secular variation) that were submitted to the IAGA Working Group V-8 by the deadline in February 1999. A description of the data used and the method of modelling is summarised for each candidate model. The models are then compared with one another and with recent data from observatories and magnetic surveys. It is concluded that none of the candidate main-field models is sufficiently good for an IGRF and that a new model should be derived using Ørsted data.
\end{abstract}

\section{Introduction}

For IGRF 2000, four models, each comprising a main-field model for 2000.0 and a predictive secular-variation model for 2000.0-2005.0, were submitted for evaluation to IAGA Working Group (WG) V-8. The models were submitted by Institut de Physique du Globe de Paris (IPGP model), British Geological Survey/US Geological Survey (UKUS model), IZMIRAN (IZM model) and by the chairman of WG V-8 (IGRF7). Based on notes submitted to WG V-8 with the models, a brief description of the data used and the method of modelling for each of the candidate models is given; more details can be found in other papers in this issue. The models are then compared with one another and with recent data from observatories and magnetic surveys.

\section{Data Used and Modelling Method for the Can- didate Main-Field Models}

IPGP Observatory, repeat station and marine data were used; there were no satellite or Project MAGNET data. A weighting scheme was used based on geographical distribution and data type. No synthetic data were used so the model is almost independent of previous models.

UKUS POGS satellite, Project MAGNET, observatory and repeat station data were all used, though indirectly by updating an earlier model to epoch 2000.0 with new secular-variation models. No marine data were used. A weighting scheme based on latitude and data type was used.

IZM Observatory data and synthetic data on a $20^{\circ}$ latitude/longitude grid from a previous IZMIRAN model were used. Limited information was submitted with the model.

IGRF7 This is the 1995.0 model updated to 2000.0 using 7th generation IGRF secular-variation model (IAGA Division V, Working Group 8, 1995).

Copy right (C) The Society of Geomagnetism and Earth, Planetary and Space Sciences (SGEPSS); The Seismological Society of Japan; The Volcanological Society of Japan; The Geodetic Society of Japan; The Japanese Society for Planetary Sciences.

\section{Data Used and Modelling Method for the Can- didate Secular-Variation Models}

IPGP Only observatory data were used. Predictions to 2000.0 were based on monthly means but those beyond 2000.0 were based on annual sets of spherical harmonic coefficients rather than on data from individual observatories.

UKUS Predictions were based on secular-variation data from individual observatories and repeat stations. Synthetic data from a secular-variation model which included POGS (2.7 year duration) and Project MAGNET data were also used.

IZM A natural orthogonal components analysis based on annual means and predictions from 28 observatories was used.

IGRF7 Secular variation is effectively assumed to be constant for the 10-year period 1995.0-2005.0.

\section{Inter-Model Comparisons}

The models were first compared with each other using the same method as in Macmillan and Barraclough (1997). Global RMS differences were computed (Tables 1 and 2) and plots of differences in $X, Y, Z$ and $F$ were made. It should be noted that the global RMS differences for the $X$ and $Y$ components assume orthogonality of these components over the sphere. According to De Santis et al. (1995) this is not the case but the values computed here are still useful for comparative purposes. Some very large differences $(>1000$ nT) occur, predominantly in areas where there are no data or only POGS satellite scalar data. Even in areas where there are data there are still some large differences (>200 nT). The global RMS differences between main-field models are at least twice those reported for candidate IGRF models for 1995.0 (Macmillan and Barraclough, 1997).

\section{Comparisons of Models with Data}

The candidate models were compared with observatory annual means, repeat station and other land magnetic survey data (reduced to quiet levels) and marine scalar data (110 km 
Table 1. RMS differences between candidate IGRF main-field models for 2000.0.

\begin{tabular}{lcccc}
\hline & $X(\mathrm{nT})$ & $Y(\mathrm{nT})$ & $Z(\mathrm{nT})$ & $F(\mathrm{nT})$ \\
\hline IGRF7/UKUS & 67 & 65 & 106 & 141 \\
UKUS/IZM & 136 & 129 & 206 & 278 \\
IZM/IGRF7 & 134 & 132 & 207 & 280 \\
UKUS/IPGP & 172 & 175 & 270 & 365 \\
IPGP/IGRF7 & 175 & 190 & 285 & 384 \\
IPGP/IZM & 230 & 220 & 348 & 471 \\
\hline
\end{tabular}

Table 2. RMS differences between candidate IGRF secular-variation models for 2000.0-2005.0.

\begin{tabular}{lcccc}
\hline & $X(\mathrm{nT} / \mathrm{yr})$ & $Y(\mathrm{nT} / \mathrm{yr})$ & $Z(\mathrm{nT} / \mathrm{yr})$ & $F(\mathrm{nT} / \mathrm{yr})$ \\
\hline IGRF7/UKUS & 9 & 8 & 14 & 18 \\
UKUS/IZM & 8 & 10 & 15 & 20 \\
UKUS/IPGP & 10 & 11 & 17 & 23 \\
IZM/IGRF7 & 10 & 13 & 19 & 25 \\
IPGP/IZM & 11 & 13 & 19 & 25 \\
IPGP/IGRF7 & 14 & 15 & 24 & 32 \\
\hline
\end{tabular}

Table 3. RMS deviations of models from observatory annual means in $X, Y$ and $Z$ (nT).

\begin{tabular}{cccccc}
\hline Year & Number & IPGP & UKUS & IZM & IGRF7 \\
\hline 1995 & 473 & 254 & 239 & 254 & 215 \\
1996 & 419 & 250 & 238 & 257 & 210 \\
1997 & 389 & 258 & 240 & 269 & 213 \\
1998 & 154 & 267 & 234 & 294 & 231 \\
All & 1435 & 255 & 238 & 263 & 215 \\
\hline
\end{tabular}

Table 4. RMS deviations of models from repeat station and other land magnetic survey data in $X, Y, Z$ and, where any of these are missing, $F$ (nT).

\begin{tabular}{cccccc}
\hline Year & Number & IPGP & UKUS & IZM & IGRF7 \\
\hline 1995 & 1432 & 228 & 196 & 238 & 190 \\
1996 & 438 & 281 & 270 & 282 & 216 \\
1997 & 272 & 261 & 260 & 281 & 195 \\
1998 & 285 & 327 & 313 & 335 & 231 \\
All & 2427 & 253 & 230 & 262 & 200 \\
\hline
\end{tabular}

Table 5. RMS deviations of models from marine $F$ data (110 km along-track averages of quiet data) (nT).

\begin{tabular}{cccccc}
\hline Year & Number & IPGP & UKUS & IZM & IGRF7 \\
\hline 1995 & 142 & 262 & 258 & 619 & 217 \\
\hline
\end{tabular}

along-track averages of quiet data), all for 1995 and onwards. The results are presented in Tables 3, 4 and 5. Some of these data have not been used in any of the candidate models so constitute a partially independent dataset.
Model values were derived from a linear interpolation in time between the 7th generation IGRF at 1995.0 and the candidate model for 2000.0. The RMS deviations are about $30 \%$ larger than the equivalent deviations computed when 
considering the candidate models for the 7 th generation IGRF (Macmillan and Barraclough, 1997).

\section{Conclusions}

None of the candidate models are particularly good. The differences between models and differences between models and data are all much greater than those calculated for the 7 th generation IGRF candidate model evaluation. The UKUS and the IGRF7 models are most alike, for both the main-field and the secular-variation parts. In addition, these two models fit the data marginally better than the other candidate models. It is recommended that a main-field model for 2000.0 be computed using Ørsted data and that this is considered for IGRF 2000.
Acknowledgments. This paper is published with the permission of the Director, British Geological Survey (Natural Environment Research Council).

\section{References}

De Santis, A., C. Falcone, and F. J. Lowes, Remarks on the mean-square values of the geomagnetic field and its components, Annali di Geofisica, XXXVIII(2), 167-175, 1995.

IAGA Division V, Working Group 8, International Geomagnetic Reference Field, 1995 Revision, J. Geomag. Geoelectr., 47, 1257-1261, 1995.

Macmillan, S. and D. R. Barraclough, An evaluation of candidate geomagnetic field models for DGRF 1990 and IGRF 1995, J. Geomag. Geoelectr., 49, 263-278, 1997.

S. Macmillan (e-mail: S.Macmillan@bgs.ac.uk) 